\title{
Why do registered nurses choose to offer complementary and alternative medicine?
}

Berit Johannessen

University of Agder, Norway

\begin{abstract}
The use of Complementary and Alternative Medicine (CAM) is increasing in Norway. A growing number of nurses choose to offer CAM, and the purpose of the study presented in this article was to examine the reasons for their choices. Fieldwork including interviews with 20 nurses offering CAM was conducted. The results showed that the nurses in general are not satisfied with the public health service. They had four main reasons for their choice to offer CAM: 1 . A desire to perform holistic nursing. 2 . A tendency to value self-realization. 3. A wish to experience meaning in their work and develop a stronger professional identity. 4. A freedom to mix care and cure. The results of this study are also discussed in view of medicalization.
\end{abstract}

Key words CAM, nursing, holism, professional identity

\section{INTRODUCTION}

This article will examine why Norwegian nurses choose to offer CAM and present a summary of doctoral work completed in 2006 (Johannessen, 2006). The work was a qualitative study using fieldwork and included interviews with 20 Norwegian nurses offering CAM. The therapies offered were acupuncture/Chinese medicine, qi gong, kinesiology, homeopathy, healing/spiritual healing, reflexology, aromatherapy, Rosen therapy, Bach flower essences, Ma-Uri massage, psychodrama therapy, craniosacral therapy, nutrition/diet, bioresonance, naturopathy, phytotherapy, ayurvedic medicine, and anthroposophical medicine.

Because CAM was a growing market in the Norwegian society, the government appointed a committee in 1998 (NOU 1998:21). This committee examined the alternative medicine's place in Norwegian society and had a number of different proposals to establish CAM as a serious part of the public health market. One proposal was the introduction of a new law, applicable from January 2004 and another was the establishment of a public registration system. Two other important results were the establishment of a research center, www.nafkam.no, and a national information center, www.nifab.no.

Studies show that nearly $50 \%$ of the Norwegian population use CAM, even if they have to pay for it themselves (the public health service is almost free for Norwegian residents) (www.nifab.no). Studies have also revealed a lack of knowledge and different attitudes to alternative treatments among Norwegian health personnel. For example, nurses are more positive than doctors; studies also show that nurses themselves use CAM when they become sick, and many of them educate others in CAM in addition to nursing (Risberg 2003).

To understand why nurses choose to offer CAM, it can be

*Correspondence: Berit Johannessen

E-mail: berit.johannessen@uia.no

Received July 15, 2011; Accepted February 22, 2012; Published

February 29, 2012

doi: http://dx.doi.org/10.5667/tang.2011.0021

(C)2012 by Association of Humanitas Medicine useful to look at the general trends in nursing. Nursing, as a practical profession and as a scientific discipline, has developed in different directions over recent years. Nursing science is a young discipline with a strong influence from the United States, where most of the nursing and caring theories are developed. Practical nursing, however, is governed by other theories and claims, such as medical, economical, and organizational theories. The gap between theoretical and practical nursing creates a series of debates among nurses. One of the debates today is connected to so-called "management thinking". This means that in practical nursing the focus is mainly on productivity, output, and profits. Norwegian nurse philosophers claim that this "kills" the professional discretion and the holistic approach essential to nursing care. In theoretical nursing, on the other hand, caring for the "whole person" is emphasized. The practical nurses of today have a feeling of coming up short, and that there are few opportunities to realize their ideals. Studies show that nurses leave the profession often because they are frustrated and burned out when they are not able to be the nurses they would like to be (Johannessen, 2006).

In the humanistic/phenomenological tradition, several theories in nursing have been developed, some of which are characterized by metaphysics and philosophy. These theories largely include different CAM therapies (such as therapeutic touch and aromatherapy) in nursing. Well-known theories within this tradition are Jean Watson's theory of transpersonal nursing (Watson, 1999), Newman's theory of health as expanding consciousness (Newman, 1994), and Martha Rogers' theory of unitary human beings (Rogers, 1990). However, these theories are not well known in Norway.

\section{Reasons to choose CAM}

In my study of nurses who choose to work with CAM, I found that they had four main reasons. These will be briefly presented and discussed below.

\section{A desire to perform holistic nursing}

Nurses who choose to offer alternative therapies call themselves holistic nurses. This means that they will emphasize both CAM and nursing care. A key word in their holistic 
orientation is connection. This refers to the connection between human being and nature (including animals), between people, between the person and God or some other spiritual force, and the connection between body and soul. The word energy (qi, reiki, prana, vital force) is used to explain this connection. All these connections are essential for health and illness. In Norway, "holistic nursing" is not recognized as a specialization in nursing as it is, for instance, in Britain and the United States (http://www.ahna.org/default.aspx). Internationally, this tradition is established with holistic nursing education programs, associations, and research journals.

By using the concept of holism, the informants in my study both confirm that they are alternative therapists and clarify their nursing standpoints. They think and act from a different paradigm than the medicine and public health services, which they perceive to be reductionist, with too little focus on the importance of connections, especially between body and soul and between the individual and one's environment. By having a holistic approach, they emphasize the mental and spiritual aspects of health and illness, which they believe are underestimated in nursing education and in the public health service. By using the term holistic, they also express a criticism of the existing paradigm (Johannessen, 2006, 2009a).

The concept of holism is also a key concept in the New Age movement. The term may be said to describe a sanctifying of reality in which all living things are perceived as sacred or divine. "Something" pervades all life, ties it together, creating balance and harmony and should be respected. This view is also expressed in more recent theories of nursing, where health, ecology, and religiosity are mixed. Informants tell of how they experience contact with the divine energy of nature and how they can use divine energy in the treatment of the sick. In this way, new religiosity and nursing run together. The mixing of religion and health is perceived by the informants as a positive opportunity, but biomedical doctors claim it is a junk mixture, and Christian health care workers experience a religious dilemma in the face of alternative treatments because holism is perceived as a rival to Christianity. Some Christian health workers warn people not to seek out alternative therapists.

There are many unresolved issues with regard to theoretical nursing, practical nursing, and CAM in terms of what is a holistic approach, particularly with regard to the spiritual aspect of health and disease. The relationship between nursing and Christian heritage in our Western culture is also blurred. Because holism is so diverse, it is a vague term for health workers and there are many problems with using the term (Johannessen, 2006, 2009a).

\section{Valuing self-realization}

The nurses in this study highlighted the importance of self and self-realization in relation to health and illness. They also experienced self-realization by resigning from their jobs in the public health service to pursue jobs in the CAM business. They connected these terms both to the understanding of diseases and to their treatment methods. The experience of illness is perceived as meaningful because it provides opportunities for self-realization. Some of the informant nurses also believed that illness is something the higher self chooses. Such an understanding is linked to New Age beliefs about reincarnation. CAM nurses can use various methods to help patients in the self-development process, such as healing, massage, meditation, qi gong, and creative activities. These therapies will help patients to connect with their inner selves and might help them understand why they are ill. To gain such insight might be considered crucial for the healing process (Johannessen, 2006, 2011).
The concept of self is often mixed with the concept of the soul, and there is an unclear relationship between psychology, nursing, and alternative religiosity. Nurses who choose CAM will often mix religion and health, and the religious aspect is highlighted as central to health care. The connection between body and soul is emphasized; therefore, for some informants the idea of reincarnation will be natural (Johannessen, 2006, 2011).

\section{Experiences of meaning and professional identity}

Nurses who choose to work with CAM still perceive themselves as nurses but in a slightly different way than before. They emphasize that CAM therapists and nurses are in line with the values they consider important in nursing. They see no problems with including CAM theories, such as the theories of qi. Self-healing resources, holism, empowerment, and selfdevelopment are considered central. By choosing to offer CAM they experience a stronger professional identity than they would as employees in the public health service. One of the reasons for this may be the changes in the public health service, which are strongly influenced by the ideas of "New Public Management", focusing on efficiency, production and specialization. The possibilities for practicing holistic nursing are considered to be threatened and informants in the study want to free themselves from rigid professional roles, particularly from the role of the physician's assistant. Further, professional identity in nursing is defined very broadly, and informants see no problems with the integration of the CAM philosophy and alternative therapies into the professional identity of nursing (Johannessen, 2004, 2006)

Professional identity is also linked to a sense of meaning in the job. A broad definition is given by Fagermoen (1995):

Professional identity is defined as the values and beliefs held by the nurse that guide her thinking, actions, and interactions with the patient. Professional identity represents the nurse's philosophy of nursing, i.e., what it means to be and act as a nurse.

As this definition outlines, the professional identity is determined by the individual nurse herself. Nursing as a profession is not connected to a certain theory of man or disease, and it can be performed under different medical paradigms, such as Traditional Chinese Medicine and ayurvedic medicine, as well as Western biomedicine.

Developments in society and in general and health care service in particular, have led to an increasing need to clarify the role of nurses. The fact that an increasing number of nurses quit their jobs in the public health service to offer CAM can be understood as a sign of dissatisfied nurses. The health care system does not give nurses the opportunities for professional and personal development that they want. On a theoretical level, CAM can be included in nursing, but on a practical level in the public health service there is little room for including CAM in health care and nursing (Johannessen, 2004, 2006).

The identity problems in nursing may also be connected to the tension between modernity and tradition. Modernity's emphasis on science as the most valued form of knowledge has had a strong influence on nursing. This is made visible today in the form of increased focus on evidence-based practice. Evidence-based practice is usually understood as practice based on quantitative research focusing on documented effects, with biomedical explanations. Nurses who choose CAM align themselves more freely with claims about science, and increasingly value intuition, experiential knowledge and tradition. These aspects contribute to the lukewarm attitude they are met with in research environments, where CAM is not perceived as evidence based (Johannessen, 2004, 2006). 


\section{Freedom to mix care and cure}

One of the most important distinctions in the public health service is the distinction between cure/treatment and care/nursing. Curing is focused on discrete bodies and the disease and often follows standard treatment procedures. Caring is focused on the whole person and how the person experiences one's illness. This distinction is also a power relationship. Working with care is culturally coded as female, is considered practical and concrete, and is often discouraged in Western culture. Working with medical treatment/cure, however, is coded as male and considered theoretical and abstract, and has high social status. Informants in my study challenge this distinction, because as CAM nurses, they do not distinguish between care and cure. CAM-practicing nurses may have a role that is a mixture of a doctor and a nurse where the disease and the sick person are treated individually and in a unique way (Johannessen, 2006, 2009b).

When nurses choose to work with CAM, most of them offer such treatments outside the public health service. They will have to start their own private businesses, which is very unusual among registered nurses in Norway. The private market is a new arena for nurses, where they compete to some extent with doctors. Until now, it does not seem that doctors have perceived CAM nurses to be strong competitors. It seems that patients are using both doctors and CAM nurses because each has strengths in different areas. However, the relationship between doctors and nurses may be affected by nurses working independently with cure as well as with care. The relationship between doctors and nurses is changing. For example, more and more nurses in the Norwegian public health service are responsible for delimiting "physician tasks" under the doctor's authority. At the same time, many nurses report that they do not have time for the independent nursing function because they must give priority to being the doctor's assistant. The subordinate and downgraded role nurses are assigned in the public health system in relation to doctors and medicine contribute to nurses choosing to quit and offering CAM (Johannessen, 2006, 2009b).

In different ways, gender is a relevant topic within the CAM area. The gender dimension runs from male doctors and female nurses to the use of the terms feminine and masculine for CAM and conventional medicine, respectively. The concepts of feminine and masculine are problematic and may not necessarily be linked to the terms woman and man. The perception in the CAM field is nevertheless clear: there is an imbalance in Western medicine, with a preponderance of masculine values at the expense of feminine values. This is also seen as a power/powerlessness relationship. Informants in the study want to free themselves from what they call medicine characterized by masculine rationality. A holistic approach is perceived to be based on feminine values and feminine energy. Given the human capacity for self-healing, informants will provide treatments they call holistic. These treatments appeal to women, especially nurses (Johannessen, 2006, 2009b).

In Norwegian society, as in Western societies in general, individualism is valued. Each person's personal experiences, needs, and desires are essential and there is an increasing focus on self-development. Freedom and independence must be sought. Nurses choose CAM because they will not be bound by the roster, poor wages, and the role of a doctor's assistant. However, not every CAM nurse earns a lot of money; it is difficult to run one's own business. Some of them continue to have part-time jobs in the public health care service (Johannessen, 2006, 2009b).
Nurses who choose to offer CAM will offer different therapies, and some of them are aimed at healthy people to prevent diseases. Norway is one of the richest countries in the world and people want to spend money on health. CAM therapists are part of a growing health care market in which health is increasingly sold as a commodity. They are marketing their services, not only to help people, but also by trying to create needs. It is not just the sick who are encouraged to use CAM, but also all those who do not experience themselves as whole people or who seek wellness and beauty (Johannessen, 2006).

The concept of medicalization is used to describe a process in which medicine plays an ever increasing role in society and where more and more people are defined as patients or belonging to risk groups. The professional health care service has expanded and taken over much of the work previously carried out in the home by family and caregivers. At the same time, there is an ever increasing part of society that is characterized by scientific medicine and its views. To the extent that CAM therapies can be said to belong to the medical sphere, it has largely contributed to the medicalization, for instance, by a host of new "diagnoses" and by offering treatment for things that were previously considered to be normal conditions (Johannessen, 2006, Lian, 2006). Because most of the patients using CAM are women, Kraft (2000) claims that CAM contributes to the view of the female body as a "constantly sick" body. This makes women weak and powerless.

If we consider CAM therapists to be medical experts who tell people how they should live a healthy life or what complaints they should seek treatment for, this can be understood as an expression of medicalization.

On the other hand, nurses who provide CAM can be viewed as an extension of the social network that promotes self-help. A lot of CAM therapies focus on prevention (such as qi gong and yoga). Many people find that CAM therapies have improved their quality of life and given them useful tools to take greater responsibility for their own health, thus allowing them to become independent of professional health workers.

\section{CONCLUSION}

The question this article has considered is why nurses choose to offer CAM. The results show that the choices are related to nurses' personal experiences, conditions in the public health service and society in general, and trends in nursing. Cultural processes such as new religious movements and market mechanisms also play important roles. All these work together. One thing is certain: CAM is here to stay in Norwegian society and among Norwegian nurses. Further research will show to what extent these healthcare givers succeed in this business.

\section{CONFLICT OF INTEREST}

The authors have no conflicting financial interests.

\section{REFERENCES}

Fagermoen MS. The meaning of nurses' work: A descriptive study of values fundamental to professional identity in nursing. Akademika ed. (Oslo, Island: Thesis of Institute for Nursing Science), 1995.

\section{Will CAM support medicalization?}


Kraft, S.E. Sykdomsbilder. In: Engedal,LG \& Sveinall AT ed. (Troen er løs. Trondheim, Norway: Tapir forlag). pp. 42-55, 2000.

Johannessen B. Norwegian nurses choice to work with alternative/complementary therapy: How will this affect their professional identity? International Journal for Human Caring. 2004;8:48-52.

Johannessen B. Sykepleiere i alternativ behandling. (Bergen, Norway: Thesis of University of Bergen), 2006.

Johannessen B. Holisme i Sygepleje. Alternativ behandling og nyreligiøsitet. Klinisk Sygepleje. 2009a;23:22-33.

Johannessen B. Why do Norwegian nurses leave the public health service to practice CAM? Complement Ther Clin Pract. 2009b;15:147-151.

Johannessen B. Realization and development of self in CAM nurses and CAM: A qualitative study in nursing, inspired by cultural science. Int J Human Caring. 2011;15:2.
Lian O. Den modern eos-myten om medikalisering som modernitetsfenomen. Sosiologisk Tidsskrift. 2006;1:68-87.

Newman M. Health as expanding consciousness. (New York, USA: National League for Nursing Press), 1994.

Jarle Aarbakke. Alternativ Medisin. (Oslo, Norway: Statens forvaltningstjeneste), 1998.

Risberg T. Kolstad A. Alternativ medisin-holdninger og bruk blant sykehusansatte leger, sykepleiere og kontorpersonell. Tidssk Nor lægeforen. 2003;123:604-606.

Rogers M. Nursing: A science of unitary irreducible human beings. In Barett E M ed. Visions of Rogers' science based nursing. (New York, USA: National League for Nursing), 1990

Watson J. Postmodern nursing and beyond. $1^{\text {st }}$ ed. (London, UK: Churchill Livingstone), 1999. 